\title{
Observação e ordem: "rascunhos" a uma Epistemologia do (com)plexus
}

\author{
Observation and Order: "Drafts" to an Epistemology of Complexus
}

Leo Peixoto Rodrigues

Universidade Federal de Pelotas, Brasil

\section{RESUMO}

O debate sobre observação e ordem proposto neste artigo, fruto de pesquisas teóricas nos campos da epistemologia construtivista e complexa e da teoria sistêmica, parte de uma discussão "não clássica" do debate filosófico-epistemológico sobre observação. Centrando-se em reflexões de caráter mais propriamente epistemológico que filosófico, este artigo dá relevo aos avanços obtidos pelo próprio conhecimento científico contemporâneo, de modo interdisciplinar, considerando disciplinas tais como a física da termodinâmica, a ciências da cognição, a biologia evolucionista, a sociologia dos sistemas sociais. Em outros termos, antes de pretender fazer qualquer filosofia da ciência, faz, mais propriamente, uma espécie de ciência filosófica. O artigo apresenta como coluna dorsal, que lhe dá sustenta a toda argumentação ao longo de seu desenvolvimento, a problematização reflexiva que envolve os conceitos de observação, observador e observado, com as noções de ordem e desordem, essenciais para construção da realidade, tida (e vista) como "objetivada". Especificamente ele busca, a partir dessas categorias, propor um esboço geral -alguns "rascunhos"- de como a "realidade" se apresenta e se estabiliza de forma interativa e complementar, mas sempre precária e contingente, envolvendo a permanente indeterminação/determinação construtivista.

PALAVRAS CHAVE: Observação/ observador; Ordem/ desordem; Indeterminação/ complementaridade; Epistemologia complexa

\section{ABSTRACT}

The debate on observation and order proposed in this article results from a theoretical research in the fields of constructivist and complex epistemology and systemic theory. So, it does not start from a "classical" discussion of the philosophical-epistemological debate on observation. The discussion here proposed relates more specifically to epistemological reflections rather than philosophical ones. The article gives relevance to the advances made by contemporary scientific knowledge in an interdisciplinary way, considering disciplines such as: the physics of thermodynamics, the sciences of cognition, evolutionary biology, the sociology of social systems. Before pretending to do any philosophy of science, it intends to make a kind of philosophical science. The article presents as a dorsal column, which gives support to all arguments throughout its development, the reflexive problematization that involves the concepts of observation, observer and observed, with the notions of order and disorder, essential for the construction of reality as "objectified". Specifically, this article seeks, from these categories, to propose a general outline - some "drafts" - of how the "reality" presents and stabilizes in an interactive and complementary, although always precarious and contingent, involving permanent constructivist indetermination/determination.

KEYWORDS: Observation/ observer; Order/ disorder; Indetermination/ complementarity; Complex epistemology.

MAD, Nº 37 (2017), PP. 91-112

DOI: 10.5354/0718-0527.2017.47277

(C) CC BY-NC 3.0 CL 


\section{INTRODUÇÃO ${ }^{1}$}

$\mathrm{Na}$ filosofia, assim como na epistemologia -essa última, com crescente autonomização como ramo da filosofia, passando a ser uma espécie de "disciplina auxiliar" de cada uma das áreas ou disciplinas que compõem a ciênciao debate sobre a observação é antigo. Para não se retroceder demasiadamente, perdendo-se nos ricos e laboriosos meandros, desde os gregos, sobre o papel e as possibilidades e limites da observação na obtenção e/ou produção de conhecimento científico, aponta-se, aqui, como marco moderno importante, o ceticismo do filósofo escocês David Hume, na primeira metade do Século XVIII. Adverte-se, entretanto, de imediato, que não se pretende neste artigo retomar a discussão sobre observação dentro do enfoque (de características mais clássicas) abordado no decorrer do século XX. Enfoca-se, brevemente, aspectos desse debate, apenas como ponto de partida e para salientar o caminho distinto que se vai tomar. $O$ debate sobre "observação" e "ordem", aqui proposto, vai partir de algumas reflexões cujo caráter é nuclearmente epistemológico, por um lado, mas também apoiado em debates científicos contemporâneos transdisciplinares, por outo lado, ocorridos mormente no âmbito das ciências em geral, como na física da termodinâmica, nas ciências da cognição, na biologia evolucionista, na sociologia dos sistemas sociais. Neste sentido, como não poderia ser diferente, transgrediremos - por vezes abruptamente-algumas fronteiras disciplinares.

\section{OBSERVAÇÃO COMO OBJETO DE DEBATE NO SÉCULO XX}

Em Investigación sobre el conocimiento bumano, ${ }^{2}$ Hume sustenta seu ceticismo, em boa medida, rejeitando o princípio da indução, tal como se aplica à causalidade. Propõe, em outros termos, que se "A" foi encontrado frequentemente acompanhado por " $B$ ", nada nos autoriza inferir que haja uma relação causal entre "A" e "B" e que "A" é causa de "B" e "B" efeito de "A". O princípio da indução, cuja base é a observação, o qual afirma que a partir de uma série de observações singulares é possível generalizar, não se sustenta, segundo Hume, nem do ponto de vista Lógico nem do ponto de vista

\footnotetext{
${ }^{1}$ Quero agradecer a leitura atenta e as sugestões feitas pelo Dr. Guilherme Brandão, ao mesmo tempo em que reafirmo minha inteira responsabilidade pelos caminhos e/ou descaminhos deste artigo.

2 Usamos a edição em espanhol de 1989.
} 
psicológico. Do ponto de vista lógico, não se justificaria raciocinar no sentido de que pelo fato de ter havido repetidamente um determinado tipo de acontecimento, se estaria autorizado a dizer que no futuro (mesmo próximo) tal acontecimento repetir-se-ia do mesmo modo. Essa garantia, logicamente não existe. Do pondo de vista psicológico, as pessoas se conduzem por expectativas e acreditam que experiências pretéritas podem garantir a regularidade de experiências futuras (Hume 1989, Russel 1982).

A ciência, não obstante as advertências de Hume, seguiu produzindo seu conhecimento com base na indução. Como bem menciona Bryan Magee (1979: 23): "o problema da indução, que tem sido denominado o 'problema de Hume', vem perturbando os filósofos desde o tempo de Hume até os nossos dias". Acrescenta ele que tal impossibilidade de as observações particulares garantirem a generalização, portanto a "verdade", constitui-se naquilo que "C. D. Broad, de maneira jocosa, descreveu como o esqueleto que se acha no armário da filosofia” (1976: 23).

Karl Popper (1974), ainda na primeira metade do século XX, na obra "A lógica da Pesquisa científica", foi quem retomou o problema da indução, enfrentando a sua impossibilidade lógica e propondo uma saída para assegurar o estatuto da ciência como produtora de conhecimento. Conforme menciona Rodrigues (et al. 2016: 29):

A importância dessa obra está no fato de que Popper declara a impossibilidade de a indução se constituir num método científico seguramente lógico como critério de demarcação entre ciência e não ciência. Popper vai retomar o argumento de Hume e propor-lhe uma saída "estratégica" para que se contorne o problema da indução e se continue tendo um critério para a demarcação da ciência e da não ciência, além de uma "garantia" (mesmo que temporária) para a "veracidade" das teorias científicas: a testabilidade e falseabilidade [grifos dos autores].

Seguiu-se durante todo o século XX um profundo e acalorado debate nos âmbitos da epistemologia, da filosofia da ciência, da sociologia da ciência e de outras disciplinas, que tiveram em tela a questão da observação como possibilidade de produzir conhecimento, seja ele verdadeiro ou "próximo à verdade", cuja bibliografia é abundante e diversificada. ${ }^{3} \mathrm{O}$ debate sobre a

\footnotetext{
3 Sugerimos alguns textos que julgamos importantes para aprofundamento deste debate, quais sejam: na filosofia da ciência, Paul Feyerabend (1989), Thomas Kuhn (2011), Imre Lakatos (1979, 1993), Karl Popper (1974a, 1977), Paul K. Moser (2002); na sociologia, David Bloor (1984), Harry M. Collins (1983), Karin Knorr-Cetina \& Michael Mulkay (1983), Bruno Latour \& Steve Woolgar (1986), João Nunes, \& Ricardo Roque (2008).
} 
observação, entretanto, desenvolveu-se durante o século XX (e mesmo antes) muito atrelado à possibilidade de se produzir conhecimento científico verdadeiro, baseado no método indutivo. Evidentemente que esse núcleo epistemológico -a possibilidade da observação desvelar verdades- foi intensamente problematizado com outras abordagens que se tornaram importantes no decorrer do século passado, tais como: a) a intenção, os tropeços e mesmo o declínio do positivismo lógico em "cientificizar o mundo" e sua proposta de separar o contexto da descoberta e o contexto da justificação; b) a ascensão da hermenêutica e da fenomenologia como métodos; c) o desenvolvimento da filosofia da linguagem, etc. Não vamos neste ensaio abordar praticamente nada referente à observação vinculado a essa perspectiva, posto que, como mencionamos, ela tem sido amplamente debatida. Nosso intendo é outro: o de explorar aspectos "menos evidentes" sobre a observação; aspectos pouco problematizados e cuja origem, parece-nos, ocorreu mais a partir de conhecimentos que a ciência tem trazido à tona, e menos oriundo da reflexão e do embate filosófico; oriundo talvez de reflexões epistemológicas particularizadas, "encostadas" ou aderidas a diferentes disciplinas da ciência. Em outros termos, um conhecimento proposto menos por uma filosofia da ciência, e mais por uma ciência filosófica.

\section{OBSERVAÇÃO, OBSERVADOR E OBSERVADO}

A observação, como possibilidade cognitiva de apreensão do mundo, ${ }^{4}$ vai exigir, de imediato, um observador -que não necessita obrigatoriamente nem humano nem orgânico- e um observado -que pode ser "qualquer coisa" que se distinga do observador- possível de ser observada e que no ato de observação se preste a uma operação de distinção. Estabelece-se, então, seguindo Niklas Luhmann (2007: XIV) que toda observação é uma operação de distinção. Nas palavras dele: "toda a observação está apoiada em esquemas de distinção que são capazes de distinguir alguma coisa com relação a um fundo que compõe tudo o que há a mais". ${ }^{5}$ Isto contempla, inclusive, a auto-observação. Entretanto, se se considera que a observação é um esquema de distinção pode-se, de imediato, levantar alguns questionamentos: a) a percepção da distinção operada pelo observador corresponde

\footnotetext{
${ }^{4} \mathrm{O}$ sentido de "mundo" empregado aqui, nesse primeiro momento, aproxima-se ao de um "mundo externo", no sentido alemão de Lebenswelt, isto é, de um "mundo vivido ou, mais especificamente, o "mundo-da-vida", no sentido proposto pela fenomenologia de Husserl.

5 Todas as traduções serão realizadas livremente, pelo autor, para este texto.
} 
vis a vis a uma realidade que se apresenta "lá fora" (?); b) o observado vai se mostrar do mesmo modo a qualquer operação de observação, mesmo quando o observador não seja humano (?); c) existe uma realidade no mundo independente de qualquer observação ou toda operação de distinção está inexoravelmente atrelada à "capacidade", à "possibilidade" distintiva de diferenciação daquele ou daquilo que a observa?; d) o observador seria então um referente "fixo", isto é, sempre que observasse uma mesma coisa a observaria do mesmo modo (?); e) o mundo seria um referente fixo ou instável às observações, a todas elas, em que unidade de tempo?

A partir destes primeiros questionamentos levantados é importante que se estabeleçam (e se assumam) alguns marcos iniciais à observação. Toda observação é uma operação de distinção -isto significa dizer primeiramente que o ato de observar parte de uma inescapável premissa analítica, ${ }^{6}$ ou melhor, analítica porque autoanalítica, uma vez que, para que a observação seja possível, o observador já parte de si próprio como resultado de uma operação de distinção com relação ao "resto do mundo" para, só assim, operar as demais possíveis distinções do/no mundo. É esse o esquema que permite, inclusive, a auto-observação, uma vez que somente uma diferenciação pode diferenciar. Isto posto, tem-se que a indiferenciação não pode se constituir em "algo", portanto não pode operar qualquer distinção. Somente uma unidade (diferenciada), atuando num espaço e num tempo específicos, observa e opera diferenciações, não podendo escapar de sua própria (auto) diferenciação.

Neste sentido, a "lógica" da observação não pode ir além, ultrapassar a lógica do observador. Isto significa dizer que todo o esquema de distinção (entre os objetos do mundo) fica contido nos limites cognitivos daquele ou daquilo que opera a distinção. Como menciona Arnold (2004: 11): "a lógica da observação não pode sobre passar a lógica do observador". Isto autoriza, em tese, um deslocamento daquilo que pode ser tomado como a "realidade", a "verdade" o "mundo", em termos de diferenciação com relação aos seus "objetos", para a possibilidade/capacidade do operar "cognitivo" do observador. É isto que, de algum modo, permite (e justifica) o deslocamento de um realismo epistemológico, para um construtivismo epistemológico: se algo atua no mundo de forma prática ou ativa, por exemplo, "modela esse mundo" a partir dos meus esquemas de distinção. Acredita-se que foi esse o sentido que Humberto Maturana e Francisco Varela (1980: 8,

${ }^{6}$ No sentido grego do termo: ana $=$ separação; lise $=$ quebra. 
1999: 53) quiseram dar à afirmação: "Todo o dito é dito por um observador". Essa frase se tornou muito conhecida nos estudos da cognição; retornar-se-á a ela mais adiante.

Para que se siga problematizando a observação propõe-se certo deslocamento (heurístico) para o "lugar/estado" do observado. Esse esforço cognitivo "empático" permitiria olhar a partir do ponto de vista do observado, do distinguido ou do "operado". Para esse esforço, é mister que se retome a Segunda Lei da Termodinâmica que tem dito, conforme bem salienta Erwin Schrödinger (1997: 80), que: "as leis da física [apontam para] a tendência natural das coisas caírem em desordem". Isto é, tudo que está ordenado não permanecerá ordenado, pois existe uma "lei", uma "tendência natural" à dissipação, à desordem. Em outras palavras, a lei da termodinâmica diz que, na prática da vida cotidiana, nada é ad perpetuam. Pois bem, se aquilo que se diferencia do observador que observa (inclusive ele mesmo como "objeto" da autodistinção) tende à desorganização, à desordem, é possível se imaginar que uma entropia máxima (no mundo) probabilizaria a possibilidade de ausência máxima de ordem, portanto a tendência à impossibilidade extremada de diferenciação, posto que o indiferenciado não pode implicar em qualquer distinção. Isso acarretaria na impossibilidade (absoluta) de observação, incluindo a auto-observação; ${ }^{7}$ lembre-se, pois, que observar é operar distinção. Como seria possível haver distinção quando nada é? Tudo se calaria! Nada haveria, tampouco o observador. Acresce-se, assim, a questão da ordem à problematização da observação e, corolariamente, pode-se dizer que tudo que é, é ordem ou está implicado em ordem. Retornaremos a essa afirmação mais adiante.

O deslocamento (heurístico) proposto anteriormente para o "lado" do observado implica em "dar realismo" a ele, faz com que se assuma, de imediato, que todo o observado (já) é (já que produto de distinção); tem de necessariamente ser, posto que quando nada é, torna-se impossível falar em "lados". Ao se considerar a afirmação de que tudo é; há de se considerar, então, que tudo é ordem e, paralelamente, o fato de que a "realidade" do mundo se traduz na capacidade/possibilidade da sua descrição pelo observador, como um "ato cognitivo" de distinção, já que de alguma forma é ordem. Portanto, cabe perguntar pela "ordem do mundo": basta ser para que seja ordenado; o que é, então, a desordem (?); se tudo é ordem no mundo,

7 Conforme Heinz von Foerster (2006: 23) a autorreferência é uma "operação lógica pela qual uma operação toma a si mesma como objeto...”. 
então que "tipo" ou "quantidade" de ordem é possível capturar, operar, diferenciar, considerando a totalidade de ordem no mundo (?).

A entropia "máxima", como uma medida de desordem, ou a desordem máxima vai levar à indeterminação, ao não-ser. Nos termos de Luhmann $(1998,2007)$, vai levar à complexidade máxima, uma vez que é a ordem e somente o aparecimento dela -nos termos luhmannianos, na forma de sistema- que consegue reduzir a complexidade do "indiferenciado", diferenciando-o; aquilo que não é, em ser-ordem. De outro modo, uma entropia "mínima" (negativa ou reversa), como probabilidade de medida de ordem, vai levar a um contínuo ordenamento, a múltiplos "níveis de ordem", da mais "robusta" a mais "sutil" (se é possível que se fale assim, sem que se tenha presente, idealmente, um observador-régua). Entretanto, há de se admitir que, se por um lado, a entropia máxima levaria a uma complexidade máxima, por outro lado, um ordenamento máximo levaria, do mesmo modo, a uma complexidade máxima. A observação entraria aí como um processo de redução de complexidade e como possibilidade de equilibração do movimento (pendular) entrópico/negentrópico, que oscila entre desordem e ordem. É por este motivo que Luhmann (1998) diz que os sistemas, como unidades de ordem que se auto-organizaram, processam complexidade (também as reduzindo), mediante a construção de forma, ${ }^{8}$ de ordem, de diferenciação... de sentido. ${ }^{9}$

Pode-se dizer a mesma coisa de outro modo, projetando-a num exemplo mais "concreto". Como um exercício de menor abstração, poderse-ia supor que esse mundo (a Terra), como um todo, seja uma unidade produtora de ordem, portanto um sistema. É possível, com facilidade, justificar essa afirmação chamando a atenção para o fato de que a Terra se constitui em uma unidade cósmica "afastada do equilíbrio", nos termos de Ilya Prigogine (1996), portanto, uma unidade -desculpem a redundânciaordenada, diferenciada; nos termos de Erwin Schrödinger (1997: 83), uma unidade que "extrai entropia negativa do ambiente" (ambiente, nesse caso, o espaço, o sistema solar, o cosmos), isto é, que reverte a tendência termodinâmica à entropia máxima. A Terra seria, então, um sistema negentrópico, isto é construtor de ordem (também autorreferido, auto-organizado e auto-

\footnotetext{
${ }^{8}$ No sentido proposto por George Spencer-Brown (1972).

9 Sobre a construção de sentido ver especificamente Luhmann (1998: 77ss); para uma leitura de caráter introdutório ver Rodrigues \& Neves $(2012,2017)$.
} 
poiético) ${ }^{10}$ justamente por ter escapado à tendência de "indiferenciação" ou "nadificação" entrópica universal. É possível, então, que se considere que ela e tudo que nela esteja, seja ordem, posto que pura diferenciação. É possível que se diga ainda que só existe ordem no ser manifesto (entidade) e, portanto, naquilo que é. ${ }^{11}$ Ordem seria a manifestação do ser em diferentes entidades, considerando as leis da termodinâmica; sua não manifestação, a desordem, seria a impossibilidade de diferenciação. Assim, ter-se-ia que, tudo que é, que se manifesta (que se faz fenômeno) necessariamente é ordem -certamente a fenomenologia encontrou acolhida, mesmo que por outros caminhos, nessa mesma condução de raciocínio. Tudo aquilo que se constitui em diferença, portanto ordem, observa (-se).

Pois bem, se a observação pode ser de fato concebida como uma operação de distinção -e creio que pode-, para uma compreensão mais profunda daquilo que se chama de realidade e se acredita estar inserido, seria fundamental que se desantropologizasse a faculdade do observar. Quando a observação é vista como restrita à cognição humana esquece-se que, na base, distinguir é um "ato computacional", no sentido proposto pela cibernética. A "Máquina de Turing", concebida pelo matemático britânico Alan Turing, e construída durante a Segunda Guerra Mundial, cujos princípios matemáticos empregados para a sua concepção estabeleceram as bases da computação, fundava-se no princípio de "operar distinções", 12 portanto de executar observações.

\footnotetext{
${ }^{10}$ Humberto Maturana -e não somente ele, mas diversos teóricos da auto-organização- tem se referido em diferentes momentos sobre a dificuldade da compreensão da noção de auto-organização. Diz ele: "mais difícil de entender e aceitar do que a espontaneidade dos fenômenos biológicos, em uma cultura como a nossa, orientada ao explicar propositivo ou finalista de todo o relacionado com o vivo (...) Os processos moleculares acontecem, a cada instante, como resultado das propriedades estruturais das moléculas, e não porque alguma coisa externa os guie (Maturana 1997: 27).

${ }^{11}$ Não se fala aqui em termos heideggerianos, posto que para Heidegger dasein é operado filosoficamente numa dimensão antropologizada. Neste caso, considera-se como ente, ou ser-aí tudo aquilo que é, que se traduz em ordem e que observa, ou seja, opera "no mundo". A antropologização do observar e do "operar no mundo", tanto do ponto de vista da ciência, como o teológico, o filosófico, o ontológico, inclusive o da própria epistemologia -com o realismo epistemológico de superfície- é uma forma de redução de complexidade de uma realidade mais profunda (que se evita -ou se frustra em-acessar?). $12 \mathrm{O}$ artigo que deu origem à concepção de sua máquina foi publicado em 1936, e intitula-se: On Computable Numbers, With an Application to the Entscheidungsproblem (1936). Foerster (2006: 18s) detalha os aspectos matemáticos do funcionamento da "Máquina de Turing".
} 
Toda a matéria, ${ }^{13}$ tanto viva como inerte, observa -aqui há de se considerar inclusive compostos moleculares. A Terra só conseguiu tornar-se viva, operando distinções, isto é, através de processos observacionais. Muito antes do surgimento do homem (em torno de 200 mil anos), que representa um intervalo ínfimo de tempo, quando comparado com a vida na Terra (600 milhões de anos), a vida emergiu a partir de operações de distinções. Portanto, não apenas a desordem produziu ordem por meio de processos negentrópicos, como a matéria viva deu continuidade a tais processos, produzindo ordem a partir de ordem. ${ }^{14}$ A teoria de auto-organização, forjada implicitamente nas pesquisas da "primeira cibernética", passando a ser utilizada ampla e explicitamente sob o nome de auto-organização, a partir da década de 1970, foi sem dúvida um importante avanço interdisciplinar do conhecimento. Os estudos sobre auto-organização, de um ponto de vista epistemológico e teórico, têm contradito boa parte das explicações "clássicas" de como a matéria (viva e inerte, incluindo a informação) se comporta. Em outros termos, as perspectivas epistemológicas mecanicista, positivista e modelos matemáticos lineares ficam suprimidas em importante medida, uma vez que não há na teoria de auto-organização a concepção de "causação linear", onde sempre há aquele que causa, para que algo seja ser causado -essa é uma perspectiva epistemológica da realidade/ordem, não necessariamente a forma como ela se comporta. ${ }^{15} \mathrm{O}$ entendimento da ordem tem que ocorrer sempre na perspectiva dinâmica da "realidade", no ôntico, numa "localização" espaço-temporal, em um Lebenswelt. Neste sentido, a realidade emerge de si própria (causa sui) e, no limite, como declaram (abismados) alguns físicos quânticos, do nada, querem seja matéria ou tenha massa. Niels Bohr (Nobel de Física, em 1922) afirmou certa vez que: "tudo aquilo que chamamos de real é feito de coisas que não podem ser consideradas reais".

\footnotetext{
13 Aqui utilizamos o termo "matéria" no mesmo sentido aristotélico, ou seja: "Ora, as gerações naturais são as dos seres a que são gerados por natureza; e aquilo de que são gerados é o que chamamos de matéria..." (Metafísica, livro 7: 157. 1969).

14 Para uma discussão detalhada sobre a emergência de ordem a partir da desordem, e de ordem a partir da ordem ver: Erwin Schrödinger (1997: 79-95), Heinz von Foerster (2006: 109-121), Michel Debrum (et al. 1996), Humberto Maturana (1999), Humberto Maturana y Francisco Varela (1997), Richard Dawkins (1998), Lawrence Krauss (2013), Christophe Galfard (2016).

15 Poder-se-ia dizer que a eclosão de ordem, diferentemente do que estamos chamando de "causação linear", possa ocorrer a partir de interações multifatoriais, de forma randômica, portanto somente probabilizada.
} 
Em abordagens contemporâneas sobre a evolução, que se utilizam do conceito de autopoiesis, ${ }^{16}$ desenvolvido por Humberto Maturana e Francisco Varela (1997), em que os sistemas vivos se auto-organizam a partir de suas próprias estruturas, e sempre de forma semântica, com relação ao ambiente em que se desenvolvem, os autores afirmam:

Toda interação da identidade autopoiética acontece não somente em termos de sua estrutura físico-química, mas também enquanto unidade organizada, isto é, em referência a sua identidade autoproduzida. Aparece de maneira explicita um ponto de referência nas interações e, portanto, surge um novo nível de fenômenos: a constituição de significados. Os sistemas autopoiéticos inauguram na natureza o fenômeno interpretativo (Maturana \& Varela 1997: 47 [grifos nossos]).

Por vezes não é fácil compreender a dificuldade, mesmo em elevados meios acadêmicos, de adoção de uma perspectiva heteroantropocêntrica da observação, com relação aos diferentes processos de interação ambientesociedade. Desequilíbrios já constatados pela ciência contemporânea, relativos à relação natureza-(homem)-sociedade -questões de aquecimento global, desmatamento, questões hídricas, de poluição e de demografia, etc.-, sinalizam para as poucas chances que a humanidade tem caso não revise seus processos mais amplos de interação/observação. O refinado equilíbrio que a Terra requer como uma unidade de ordem "viva", no cosmos, depende de um delicado mecanismo de homeostase (regulação e autorregulação) que implica necessariamente em observação e auto-observação de todos os seus sistemas (nichos de ordem) que se autoproduzem em grandes conglomerados de ordem. É plausível aludir que os processos de desaparecimento de civilizações (e mesmo de espécies animais e vegetais) ocorreram, em alguma medida, porque tais civilizações não foram capazes de autoobservarem-se em seu entorno (ambiente); não foram capazes de operar sua (auto) dinâmica com seleções (atualizações) que garantissem a sua permanência como tal. A vida, como ordem, é um dado deste Universo; parece que ele tem tempo de sobra para reiniciá-la por incalculável número de vezes. Levar isso em consideração nas seleções de observações pode auxiliar na longevidade da jovem humanidade.

16 Para um maior conhecimento da noção de autopoiésis, ver: Maturana (1999), Maturana \& Varela (1997), Rodrigues \& Neves (2012, 2017a, 2017). 
4. A REALIDADE COMO RESULTADO DE INTERAÇÃO E COMPLEMENTARIDADE

Mencionou-se anteriormente que Humberto Maturana e Francisco Varela (1980: 8, 1999: 53) afirmaram que: "Todo o dito é dito por um observador". Pois bem, retornando a essa questão, deseja-se problematizá-la a partir das considerações feitas por um dos maiores estudiosos da cibernética e da cognição, Heinz von Foerster. Foerster (2006: 89 [grifos nossos]) fez referência a essa proposição de Maturana e Varela chamando-a de teorema 1. Ele propôs, entretanto, ao lado desse teorema, um outro, o teorema 2, que diz o seguinte: "Todo o dito é dito a um observador". As duas proposições seriam idênticas se não fosse por uma única preposição distinta em cada uma delas, ${ }^{17}$ mas que não apenas conduzem à problematizações importantes, como também ajuda a iluminar o encaminhamento ao ponto central dessa discussão -observação, observador e observado-, a qual se deseja abordar mais amplamente.

Ao se considerar o "Teorema 1" de Maturana, que diz: "Todo o dito é dito por um observador”, é possível constatar que tal proposição concorda com o que fora discutido anteriormente, a saber: que a observação é uma operação de distinção realizada por um observador, isto é, por aquele ou aquilo que distingue, que informa, que descreve uma determinada diferenciação, forma, ou ordem - aqui tratadas como sinônimos. Assim, essa ordem "no mundo" traduzir-se-ia em idêntica medida de possibilidade de apreensão da cognição daquele ou daquilo que a observou. Maturana quer enfocar os limites da cognição de cada (e diferente) observador, mas não apenas esse limite de apreensão, com também os limites de tradução e de exposição oriundos da própria linguagem (de cada um) utilizada para comunicar tal operação de distinção. Em outras passagens de seus escritos, Maturana (1997: 29) reafirma esse ponto de vista quando diz: "...ordem e caos são dois aspectos dos comentários explicativos que um observador pode fazer sobre o que acontece na dinâmica sistêmica espontânea de constituição de um sistema (...) que um observador pode chamar de mundo natural".

Heinz von Foerster (2006: 89 [grifos nossos]), entretanto, propõe o teorema 2, que diz: "Todo o dito é dito a um observador". Isso autoriza que

${ }^{17}$ Em inglês, teorema 1: "anything said is said by an observer"; teorema 2: "anything said is said to an observer" (Foerster 1979: 5). 
se tire algumas conclusões (ou ilações), quais sejam: a) se "todo o dito é dito a um observador" é legítimo que se pergunte pelo sujeito desse predicado, isto é: "Quem é que diz"? A resposta é: "todo o dito", ou seja, o sujeito da oração; entretanto, um sujeito indeterminado, que pode ser inclusive o "observado". Neste sentido, pode-se afirmar que existe um "observado" distinto do observador, que diz; b) Foerster, entretanto, pode também estar se referindo ao fato de que cada observador "ouve' o dito" de forma distinta uns dos outros, justamente por ter um modo ou formas de apreensão, de construção de sentido, diferenciada. Essa segunda possibilidade, com referência ao teorema 2, de qualquer modo, aproxima-se do próprio teorema 1. Entretanto, é possível inferir que o teorema 2 diga, também, que a realidade não pode, jamais, ser essencializada -como o rio de Heráclito- considerando-se qualquer fração de tempo que se meça implicaria na sua impermanência (da realidade), mostrando-se diferente não apenas no tempo, mas no espaço, uma vez que ambos estão um em função um do outro. Neste sentido, ambos os teoremas e suas interpretações possíveis parecem expressar, de forma muito próxima (para dizer o mínimo) o mesmo que o "princípio da incerteza" de Werner Heisenberg (2011, 1959) evidencia, embora aplicado à realidade subatômica. ${ }^{18}$ A realidade, desde modo, contrapondo-se aos cânones do realismo epistemológico, teria tantas formas/diferenças/ordens quantas fossem as unidades cognitivas de observação/diferenciação. ${ }^{19}$ Essa visão que se explorou do pensamento de Foerster (2006, 2003) talvez fique mais clara quando, em um de seus conhecidos artigos intitulado Disorder/order: discovery or invention?,20 ele propõe o provocativo subtítulo que questiona se a ordem/desordem são descobertas (feitas

\footnotetext{
18 O "Princípio da Incerteza" refere-se ao comportamento da "matéria" em nível subatômico, proposto por Werner Heisenberg, em 1927. Constitui-se em uma dedução matemática sobre o comportamento dual onda-partícula, que só pode ser descrito em termos de probabilidade estatística. O principio da incerteza diz que o próprio ato de observação, no mundo subatômico, perturba o objeto observado (Heisenberg 2011, 1959).

19 Tanto a perspectiva de Maturana quando a de Foerster aproximam-se daquilo que o biólogo Jakob von Uexküll teria forjado como conceito de Umwelt em sua conhecida obra Umwelt und Innenwelt der Tiere, para quem a premissa epistemológica "não é nem objetivista nem subjetivista, mas -como se descreveria atualmente- 'sistêmica'. Isso quer dizer que ele entendia o processo vital como um sistema coerente em que sujeito e objeto se definem como elementos inter-relacionados em um todo maior." (Uexküll 1909: 20s).

${ }^{20}$ Este artigo foi originalmente fruto de uma conferência em um simpósio internacional, em Stanford, publicado em seus anais em 1984. Posteriormente apareceu, em língua inglesa, a mesma do original apresentado no simpósio, em uma coletânea de ensaios sobre cibernética e cognição (dezesseis ensaios ao todo, todos de Foerster), em 2003 (Foerster 2003). Em espanhol, aparece com o mesmo título: Desorden/orden: ¿descubrimiento o invención? (Foerster 2006).
} 
no mundo) ou invenções (feita na cognição do observador). Sem entrar aqui nas especificidades mais técnicas do seu argumento, ${ }^{21}$ ele opta, e justifica, pela explicação de que a "desordem/ordem é uma invenção". Para Foerster, a captura cognitiva daquilo que é uma ou outra (ordem ou desordem), não apenas se constitui num problema de linguagem, em termos especificamente cibernéticos (de computação), mas também porque parece estar implícito em seu argumento quando ele diz: "as propriedades que se acredita residirem [nas coisas observadas], resultam ser do observador" (2006: 118, 2003: 280); acrescentaríamos: [na forma como cada observador consegue, considerando suas especificidades cognitivas, computar, traduzir aquilo que selecionou como observado ou ordem]. Mutatis mutandis isto se refere à incerteza, como princípio, aplicada à observação no plano da nossa realidade empírica.

Arthur Koestler, em uma conhecida obra chamada Janus: a Summing Up, publicada em 1978, ${ }^{22}$ propõe que se olhe a dicotomia todo/parte, a partir da metáfora de "Janus"; Jano é o deus romano de dois rostos opostos. Para Koestler (1978: 40-44), as dimensões parte e todo, devem ser vistas, ao mesmo tempo, como dimensões que ora se autoafirmam (dimensão autoafirmativa), a parte; e, como dimensões que ora se integram (dimensão integrativa), o todo. Propõe os termos "hólon" e "holoarquia", -que mais tarde ficaram conhecidos como holismo, holístico- "explicando que 'hólon' foi derivado do grego, holos (todo), assim como o sufixo on, que dá a ideia de partícula (parte) como nos vocábulos próton, nêutron". Koestler explica, ainda, que propôs os termos "para se livrarem do tradicional uso incorreto das palavras 'todo', 'parte', 'sub-todo' ou 'parte-todo', 'subestruturas'..." (Koestler 1981: 47). Se fosse estendida essa perspectiva de Koestler para a observação, considerando, também, os dois teoremas, o de Maturana e o de Foerster, seria possível supor o observador como sendo o "lado" autoafirmativo, e o observado, como "lado" integrativo. Neste caso, a "realidade", como totalidade no sentido aristotélico, (mesmo que sempre parcial) seria o resultado da interação do "lado" autoafirmativo e do "lado" integrativo. ${ }^{23}$

Considerando essa perspectiva, é possível que se conceba a observação -lembremos que por si só ela se constitui, de imediato e para dizer o mínimo, numa relação- de forma um tanto mais "refinada"; talvez "pro-

\footnotetext{
${ }^{21}$ Como físico e matemático, Forster faz uma detalhada demonstração -no molde de demonstrações de teoremas matemáticos, em Análise Matemática- para sustentar seu argumento (Foerster 2006: 116s).

22 Em português, Jano, foi publicada em 1981, edição que se está usando neste artigo.

${ }^{23}$ Sobre aspectos de uma abordagem sistêmica aristotélica ver Guilherme Brandão (2017).
} 
funda". Para tanto, propõe-se que se retorne, mais uma vez, à entropia uma âncora, "técnica" (ou lógica) para tais reflexões- e se assuma que, por um lado, a entropia opere o tempo todo dissipando ordem (ordem como aquilo que é) e que a ordem, por outro lado, vai se constituindo com (ou como) a falha (ao escapar, por escapar) desse dissipar entrópico -esse esquema já foi demonstrado, de diferentes formas, nos diversos estudos clássicos sobre entropia e consta de parte da bibliografia deste artigo. Nesse caso, pelo que já foi dito, a ordem operaria como construtora de mais ordem, ${ }^{24}$ implicando, necessariamente, em múltiplas possíveis e simultâneas relações de observação entre aquilo que supostamente experimentamos, cognitivamente, como "partes" e "todos", em determinados sítios específicos. Neste caso, a observação tornar-se-ia um processo no qual se estabelece não mais uma relação, mas uma permanente "quase-estável" interação entre a multiplicidade dos domínios (sítios) de ordem (implicando observadores e observados) que se traduzem como realidade(s). Este argumento busca teorizar sobre a passagem daquilo que se chama de relação entre observadores e observados, para o que se chamará de campo de interação: determinado sítio ou domínio de implicações (e autoimplicações) simultâneas, às quais se costuma tomar como realidade(s). Decorrem, daí, alguns desdobramentos importantes, quais sejam:

a) Os domínios "específicos" de ordem e de observação vão produzir dimensões de espaço e de tempo em conformidade com (ou a velocidade de) seus processos de autoconstrução/interação, como observações/ordens e, portanto, a construção e estabilização de realidade(s). ${ }^{25}$ Neste sentido, ordem, observação, espaço e tempo constituem-se no resultado, sempre cognitivo,

\footnotetext{
${ }^{24}$ Essa característica ou processo de certos sistemas se organizarem a partir de si mesmos tem sido fartamente demostrado pela Teoria de Auto-organização. Essa teoria também faz referência ao fato que a ordem consegue "atuar" sobre a entropia, produzindo entropia negativa, ou negentropia. Teríamos, então, o reverso da noção de dissipação, mas uma agregação, congregação, conservação de energia que se traduziria em ordem. É farta a bibliografia sobre esse tema; neste texto, já citados, indicamos Michel Debrun (1996), Heinz von Foerster (2006), Niklas Luhmann (1990). Uma das primeiras reflexões, sem que o termo auto-organização apareça, está em Erwin Schrödinger (1997), que faz uma importante digressão entre a emergência a partir da ordem e a emergência a partir da desordem, separando o vivo do inerte.

${ }^{25}$ Neste particular, temos que destacar que tal processo, a saber: autoconstrução/interação, são simultâneos, posto que toda emergência de ordem é prática, exercício de interação entre domínios dinâmicos. Sendo assim, isto implicaria, necessariamente, numa estabilização de realidade(s)/desestabilização de realidade. Em outros termos, a estabilização não procede sem desestabilização. Estas seriam as raízes mais profundas do "mecanismo" epistemológico que dá sustentação ao pós-fundacionalismo científico contemporâneo, tão caro a abordagens teóricas como as de Ernesto Laclau (\& Chantal Mouffe 1985), por exemplo.
} 
dessa interação -e como seleção de certeza. Entretanto, é importante que tenhamos em mente que ordem como manifestação do ser (no sentido heideggeriano desantropologizado), justamente porque (ela) é, fazendo-se como tal (sobretudo quando "matéria"), vai produzir, inevitavelmente, a dimensão do espaço em que se anicha e, dada a sua impermanência interativa (sua nãoessencialidade) a indissociável percepção do tempo -a historicidade tem a sua sede justamente aí. ${ }^{26}$

b) É essa imbricada construção daquilo que chamamos de realidade e que nos propicia a percepção de certo grau de estabilidade, traduzida como concretude, como certeza das quais falamos, inclusive como realidade, etc., (o "real" da epistemologia realística) que a ciência tem buscado estabelecer (e defender) o seu discurso ${ }^{27}$ - por vezes equivocadamente tomando este como o único locus possível. Essa concretude está posta mais especificamente nas "coisas", onde, inclusive "atuamos" (também) como ordem orgânica, sede da cognição, que se nomeia em um tempo e espaço específicos, estabilizandose, e transformando o sentido em semântica, apreendido como realidadelembremos que a etimologia da palavra "realidade" deriva de res, que do latim significa coisa.

c) A "realidade" estabilizada neste plano, nessa dimensão ou nesse domínio espaço-temporal tem sua "concretude aumentada". Ela se torna tanto mais "estável" (real) quanto mais transforma as "coisas" em "objetos"; objetos "desligados" e ocultados na sua própria singularidade. Em outros termos, a "realidade", quando olhada em sua superfície, parece que tanto mais "real" se torna, à medida em que as "coisas" são apartadas de suas conexões interações, constituindo-se, como bem descreve Tim Ingold (2012), em "objetos" atomizados - diferença, esta que Ingold faz entre "coisa" e "objeto. A atomização de nichos específicos de totalidades (realidades), por meio da especificidade de simbolização daquilo que eram coisas continuadas, agora transformadas em objetos específicos e estanques, isto é, sem fios ou emaranhado de significados, ${ }^{28}$ onde cada um desses objetos é reduzido em unidades de

${ }^{26}$ Não é possível a observação fora do espaço e do tempo. Somente Deus poderia fazê-lo.

${ }^{27} \mathrm{Nem}$ a própria "Interpretação de Copenhague", proposta como modelo à física quântica no final da década de 1930, mesmo incorporando o "princípio da incerteza" e o "princípio da complementaridade", conseguiram escapar do realismo epistemológico da física clássica, para se referir (conceitualmente) à física subatômica, perdurando, assim, até os dias de hoje.

${ }^{28}$ Essa nossa abordagem é também tributária da perspectiva apresentada por Gilles Deleuze e Félix Guattari em "Mil Platôs" (1995), cuja ideia central é a de rizomas, como uma metáfora das coisas que se interconectam e se sobrepõem de forma não linear. Entretanto, a perspectiva e a diferença entre "coisa" e "objeto" são muito bem descritas nesta, mais ou menos longa, passagem de Tim Ingold (2012: 28) que diz: "Nosso caminho nos leva a uma mata (...) Mas ele está repleto de objetos? Suponhamos que nos concentremos numa árvore qualquer. Lá está ela, enraizada na terra, seu tronco se erguendo e seus galhos se abrindo, balançando ao vento, com ou sem brotos ou folhas, dependendo da estação. A árvore é um objeto? Em caso positivo, como a definiríamos? O que é árvore, e o que é não árvore? Onde termina a árvore e começa o resto do mundo? Essas não são questões fáceis de responder (...) A casca, por exemplo, é parte da árvore? Se eu retiro um pedaço e o observo mais de perto, 
significação extremamente simples (iconização, em termos semióticos), é o que tem possibilitado, potencializado e mantido a perspectiva realística da ciência e do mundo. ${ }^{29}$

d) Aquilo que chamamos muito acanhadamente de complexidade, é justamente a intuição ou mesmo a consciência da insustentabilidade (se buscada) de um realismo epistemológico profundo, isto é, um realismo epistemológico que de conta da "profundidade" de onde (ou da qual) emerge a realidade, para que se apresente como tal (estável), por um lado, e para que possa constantemente se alterar, por outro lado. A filosofia, e a ciência - a primeira mais rapidamente que a segunda-, como formas de produção de conhecimento, no decorrer da modernidade, não demoraram a se confrontar com o fato de que o realismo epistemológico só pode operar quando concebido como um realismo epistemológico de superfície. É dessa forma que se a complexidade se constitui no exato limite, na específica fronteira que demarca a passagem da percepção de uma ordem estabilizada ${ }^{30}$ e "empacotada" como sentido (iconização), e aquela (ordem) que não se deixa capturar (os ciberneticistas diriam: não atualizada), percebida como impermanente, indeterminável e cuja operação de distinção vaza, o tempo todo; desfaz-se a todo instante; escorre por entre os dedos; escapa sempre frente a qualquer esforço de determinação. É por isto que a ciência (e a matemática) tem refutado ou buscado escapar, sempre que possível, das noções de complexidade, aleatoriedade, caos, indeterminação e complementaridade. ${ }^{31}$ De igual modo procede a filosofia,

constatarei que a casca é habitada por várias pequenas criaturas que se meteram por debaixo dela para lá fazerem suas casas. Elas são parte da árvore? E o musgo que cresce na superfície externa do tronco, ou os líquens que pendem dos galhos? Além disso, se decidimos que os insetos que vivem na casca pertencem à árvore tanto quanto a própria casca, então não há razão para excluirmos seus outros moradores, inclusive o pássaro que lá constrói seu ninho ou o esquilo para o qual ela oferece um labirinto de escadas e trampolins...".

29 Cientistas e filósofos atrapalham-se, constantemente, por vezes de forma um tanto infantil, em imaginarem que necessitam abrir mão (ou optar) pelo realismo epistemológico como método de condução de suas pesquisas ou reflexões. Não! O realismo, a forma de ver o mundo por esse viés, é uma conquista do pensamento ocidental que deve continuar, dentre outras possibilidades, sendo um instrumento de conhecimento e de como lidar com a existencialidade.

30 O termo "estabilizada" significa a assunção perceptiva (computacional) de espaço, de tempo, e de objetos neles nomeados (e significados) dentro de um plano (tridimensional) de ordem.

31 Michel Baranger, do Centro de Física Teórica ligado ao Instituto de Tecnologia de Massachusetts, bem descreve as razões pelas quais a Teoria do Caos se constitui num imbróglio para as hard sciences, diz ele: "Caos é a revolução anticálculo. O caos é a redescoberta de que o cálculo não tem poder infinito. No sentido mais amplo possível, o caos é a coleção daquelas verdades matemáticas que não têm nada a ver com o cálculo. E por isso é desagradável para os físicos do século XX. Em termos de aplicações, a Teoria do Caos resolve uma grande variedade de problemas científicos e de engenharia, os quais não respondem ao cálculo. Não se está dizendo que o cálculo a partir de agora será considerado fora de moda e que se deve concentrar toda a nossa atenção sobre o caos. Não, cálculo mantém todo o seu poder, mas este poder é limitado. Cálculo é apenas uma parte da verdade...” (p. 4) [tradução livre para este trabalho]. Disponível em: http://necsi.edu/projects/baranger/cce.pdf. 
não abrindo mão dos limites (seguros) da lógica clássica, amparada, inevitavelmente, pelo realismo epistemológico de superfície. ${ }^{32}$

A observação é propriedade (probabilística) de tudo aquilo que se "faz ordem", portanto, de tudo aquilo que se torna, se revela, aparece (no sentido grego do termo "fenômeno") como diferença e, paradoxalmente, indefinindo-se (ou diluindo-se) o tempo todo na dualidade autoafirmativainterativa. Abordagens tais como a teoria da forma de George SpencerBrown (1972: 1), para qual não se pode fazer uma indicação sem que se faça uma distinção; ou para a teoria autopoiética, para a qual unidade pressupõe sempre a diferença; ou mesmo para a teoria dos sistemas de Niklas Luhmann, em que sistema e entorno pressupõem-se, inexoravelmente, um ao outro, a observação se mostra, opera, em nichos específicos, como operação de distinção, não conseguindo escapar dessa "dança" que é, ao mesmo tempo, possibilidade de construção e de desconstrução de sentidos. Sentido, nesse caso, como um liame de realidade, posto que emerge a partir de seleção (estabilização) da interação polidimensional (complementar?) obsevação-observador-observado sempre "quase-instáveis".

Quando se afirma que a observação é condição de possibilidade de tudo aquilo que se faz ordem, tem-se a dimensão da dificuldade de se aceitar tal proposição, uma vez que: a) existe um antropomorfismo ao se conceber "o observar", em que se associa o conceito "observação" à necessidade de uma consciência -quando observar é, primeiramente, e tão somente, um modo de operar distinção e de produzir ordem; b) a filosofia existencialista e alguma de suas variáveis têm colocado o homem "no centro" de toda existência, tomando-o como medida daquilo que interage e se faz ordem ou não; mais que isto: como aquele que regula a construção de ordem. Ora, o homem, dada a sua recente (e talvez breve) aparição na Terra é produto de sucessivas ordenações e estabilizações anteriores a ele; a realidade, portanto, como produto de interações observacionais, não pode ficar adstrita a nenhum existencialismo, sobretudo ao humanismo. Isto implica no fato de que tudo que emerge como organização, seja "inerte" ou "vivo" - distinção essa que necessita de reflexões outras, à luz de conhecimentos atuais já produzidos pela ciência e pela filosofia-, só se faz como tal a partir

32 Uma coleção dos momentos e casos em que tanto filosofia, a ciência, e a filosofia da ciência, no decorrer de suas histórias, depararam-se com as fronteiras do determinismo resultaria numa obra realmente interessante. Para uma discussão de tais fronteiras sugere-se: Werner Heisenberg (1959), Ian Hacking $(2012,2005)$. 
de consecutivas operações de distinção (interações). Por isso, a observação se constitui na própria expressão da interação de diferentes sítios de ordem que geram, de forma simultânea e múltipla, diferenciações-interativas, trazendo à tona aquilo que se constitui em "realidade", restringindo-a, equivocadamente, a uma dimensão meramente humana. Toda e qualquer interação operada (e não só a humana) está "amparada" (posto que as institui) por unidades de sentido.

É nessa perspectiva que o sentido, como resultado de uma interação observacional, vai requerer sempre a seleção de certa(s) possibilidades operativas em detrimento de outras -mesmo a não seleção, neste caso é "escolha", portanto seleção. Se assim não fosse, jamais o "mundo" se faria realidade, posto que a "realidade", para que se teça como tal, vai impor certa estabilização de interações das diferentes ordens operadas. Luhmann (1998: 79) vai dizer que: "o sentido, em geral, e os limites de sentido, em particular, garantem o nexo insuperável entre sistema e entorno [e do mundo]"- poder-se-ia acrescentar: entre observador e observado. Ainda sobre a constituição de sentido, como distinção resultante da operação de observação, ele vai dizer: "a automobilidade do conhecimento do sentido, é por excelência, autopoiésis" (1998: 83); isto é, autopoiésis como produção de ordem, sempre a partir daquilo que já é. A observação, portanto, é uma espécie de "combustível", algo como o "élan vital", proposto por Henri Bergson, que potencializa e produz (e é potencializada e produzida) a partir de processos de interação em nichos específicos de realismo, seja pelas limitações da computação cognitivas daquele/daquilo, seja pela vastidão da "totalidade do mundo/universo" (gerados por espaços e tempos abstratos).

Caso assim não fosse, a forma/diferença/ordem (aquilo que fora operado como distinção) não seria, não existiria. Portanto, não poderia ter sido; não poderia ser "dito" por um/nenhum observador, tampouco poderia ter 'dito' a um/nenhum observador. Ao lado dos teoremas 1, de Humberto Maturana, que diz: "Todo o dito é dito por um observador"; do teorema 2, de Heinz von Foerster, que diz: "Todo o dito é dito a um observador", proponho o teorema 3 que diz: "Todo que dito/observado é ordem". 


\section{5. À GUISA DE CONCLUSÃO}

Ao penetrar no campo epistemológico com vistas a discutir alguns conceitos tais como observação/observador, ordem/desordem, determinação/indeterminação, ou até mesmo um Umwelt/Eigenwelt -no sentido proposto por Ludwig Binswanger, significa sair de qualquer zona de conforto filosófico, epistemológico, teórico ou metodológico; significa atrever-se a se colocar num território que, não obstante ao avanço do conhecimento contemporâneo, é desprotegido, vulnerável; desabitado ou habitado somente pela complexidade, ou seja, aparentemente, por quase "nada".

Por este motivo, este artigo teve a pretensão de confeccionar "rascunhos", nada mais. Apenas mais alguns rascunhos que lentamente vão se somando a tantos outros; que vão se somando a alguns esboços já bem delineados ou mesmo às poucas teorias já mais acabadas que se atrevem a olhar a realidade a partir de alternativas outras. Neste sentido, outro confortável locus de "fala científica" é perdido: o aconchego do espaço, de delimitação disciplinar do conhecimento.

Já não se acredita mais que a disciplinarização atual do conhecimento possa transcender a si mesma, fazendo do complexus o seu território tampouco se acredita que a desciplinarização do conhecimento, como método sobretudo, tenha perdido a sua função-, acredita-se, sim, que a forma como o conhecimento tem se organizado, em termos disciplinares, nos fez avançar para o conhecimento dos limites desse modelo, para os limites, no que se refere ao entendimento da "realidade", mas ainda de uma realidade de superfície, momo mencionamos. A ciência como forma de conhecimento, dentre tantas outras, é inescapável aos processos de transformação de si mesma. Como um sistema autopoiético que é, não pode evadir-se da sua própria dinâmica auto-organizativa, com relação àquilo que toma como sendo seu entorno.

Nessa perspectiva, este artigo, tudo que pretendeu fazer não foi buscar a exatidão, a precisão ou o velho "rigor" científico, à moda de um saudoso positivismo lógico. Tudo o que ensejou foi, à luz de alguma coerência (por vezes, fraca), "puxar fios" que pudessem se conectar em redes mais amplas de entendimento, de uma quase-experiência. Portanto, esforçou-se por se somar aos demais "rascunhos de conhecimento", cujo objetivo comum tem sido o de ir além de algumas das possibilidades hegemônicas de compreensão da realidade, esta, como uma aventura que nos é imposta.M 


\section{REFERENCIAS}

Aristóteles (1969). Metafísica, Vol. VII. Porto Alegre: Globo.

Arnold, M. (2004). Introducción a las epistemologías sistémico construtivistas. In F. Osorio (Ed.), Ensayos sobre socioantopoiesis y epistemología constructivista (pp. 7-15). Santiago de Chile: Ediciones Mad.

Bloor, D. (1984). Contemporary Perspective on the Sociology of Knowledge. In Sociology and Knowledge (pp. 51-75). London: New Brunswick.

Brandao, G. (2017). A acerca do conceito de sistema: da totalidade ao olho do observador. In L. Rodrigues \& Fabrício Neves (Eds), Sistemas sociais: ensaios teóricos (pp. 35-60). Porto Alegre: EdiPUCRS.

Collins, H. M. (1983). An Empirical Relativist Program in the Sociology of Scientific Knowledge. In K. Knorr-Cetina \& M. Mulkay (Eds.), Science Observed - Perspectives on the Social Study of Science (pp. 85-113). Beverly Hills: Sage.

Dawkins, R. (1998). A escalada do monte improvável. Sao Paulo: Cia da Letras.

Debrun, M., Gonzalez, M., \& Pessoa Jr., O. (1996). Auto-organização: estudos interdisciplinares. Campinas: UNICAMP.

Deleuze, G. \& Guattari, F. (1995). Mil platôs: capitalismo e esquizofrenia. Vol. 1. Rio de Janeiro: Editora 34.

Feyerabend, P. (1989). Contra o método. Rio de Janeiro: Francisco Alves.

Foerster, H. von. (2003) Undertanding Undertanding. Essay on Cybernetics and Cognition. New York: Springer-Verlag.

Foerster, H. von. (1979). Cybernetcs of cybernetics. In. K. Krippendorff (Ed.), Communication and Control in Society (pp. 5-8). New York: Gordon \& Breach.

Foerster, H. von. (2006). Las semillas de la cibernética. Barcelona: Gedisa.

Galfard, C. (2016). O Universo em suas mãos. Rio de Janeiro: Casa da Palavra.

Hacking, I. (2005). El surgimiento de la probabilidad. Buenos Aires: Gedisa.

Hacking, I. (2012). La domesticación del azar. Buenos Aires: Gedisa.

Heisenberg, W. (1959). Física y filosofía. Buenos Aires: La Isla.

Heisenberg, W. (2011). A descoberta de Planck e os problemas filosóficos da física atômica. In M. Born, P. Auger, E. Schrödinger, W. Heisenberg, Problemas da física moderna (pp. 9-28). Sao Paulo: Perspectiva.

Horgan, J. (1998). O Fim da ciência: uma discussão sobre os limites do conhecimento científico. Sao Paulo: Companhia das Letras.

Hume, D. (1988). Investigación sobre el conocimiento humano. Madrid: Alianza.

Ingold, T. (2012). Trazendo as coisas de volta à vida: Emaranhados criativos num mundo de materiais. Horizontes Antropológicos, 18(37), 25-44

Knorr-Cetina, K. \& Mulkay, M. (Eds.) (1983). Science Observed - Perspectives on the Social Study of Science. Beverly Hills: Sage.

Koestler, A. (1981). Jano: uma sinopse. Sao Paulo: Melhoramentos.

Krauss, L. (2013). Um universo que veio do nada. Sao Paulo: Paz e Terra.

Kuhn, T. (2011). Tensão essencial. Sao Paulo: UNESP.

Laclau, E. \& Mouffe, C. (1985). Hegemony \& Socialist Strategy: Towards a Radical Democratic Politics. London: Verso.

Lakatos, I. \& Musgrave, A. (Eds.) (1979). A critica e o desenvolvimento do conbecimento. Sao Paulo: Cultrix.

Lakatos, I. (1993). La metodología de los programas de investigación cientifica. Madrid: Alianza. 
Latour, B. \& Woolgar, S. (1986). Laboratory Life: The Construction of Scientific Facts. New Jersey: Princeton University Press.

Luhmann, N. (1990). Essays on Self-Reference. New York: Columbia Press.

Luhmann, N. (1998). Sistemas sociales: lineamentos para una teoría general. México DF: Anthropos.

Luhmann, N. (1999). La distinción Dios. In J. Torres (Ed), Niklas Lubmann: teoría de los sistemas sociales (artículos) (pp. 167-188). Osorno: Universidad de Los Lagos/Universidad Iberoamericana.

Luhmann, N. (2007). La sociedad de la sociedad. México DF: Iberoamericana/Herder.

Magee, B. (1979). As ideias de Popper. Sao Paulo: Cultrix.

Maturana, H. (1999). A ontologia da realidade. Belo Horizonte: UFMG.

Maturana, H. \& Varela, F. (1980). Autoposieis and Cognition: The Realization of the Living. London: D. Reidel Publishung Company.

Maturana, H. \& Varela, F. (1997). De máquinas e seres vivos - Autopoiese: a organizacão do vivo. Porto Alegre: Artes Médicas.

Moser, P. (2002). The Oxford Handbook of Epistemology. New York: Oxford.

Nunes, J. \& Roque, R. (Eds.). (2008). Objetos impuros: experiência em estudos sobre a ciência. Porto: Afrontamento.

Popper, K. (1974). A lógica da pesquisa científica. Sao Paulo: Cultrix.

Popper, K. (1974a). A sociedade aberta e sens inimigos. Belo Horizonte: Itatiaia, Sao Paulo.

Popper, K. (1977). Autobiografia intelectual. Sao Paulo: Cultrix, Ed. Universidade de São Paulo.

Prigogine, I. (1996). O fim das certezas. Sao Paulo: Unesp.

Rodrigues, L. \& Neves, F. (2012). Niklas Lubmann: a sociedade como sistema. Porto Alegre: EdiPUCRS.

Rodrigues, L. \& Neves, F. (Eds). (2017). Sistemas sociais: ensaios teóricos. Porto Alegre: EdiPUCRS.

Rodrigues, L. \& Neves, F. (2017a). A Sociologia de Niklas Lubmann. Petrópolis RJ: Vozes.

Rodrigues, L., Neves, F., \& Anjos, J. (2016). A contribuição da Sociologia à compreensão de uma epistemologia complexa da Ciência contemporânea. Sociologias Porto Alegre, 18(41), 2453.

Rusell, B. (1982). História da filosofia ocidental. Sao Paulo: Editora Nacional.

Schrödinger, E. (1997). ¿O que é vida? Sao Paulo: UNESP.

Spencer-Brown, G. (1972). Laws of Form. New York: The Julian Press.

Turing, A. (1936). On Computable Numbers, with an Application to the Entscheidungsproblem. Proceedings of the London Mathematical Society, 42(1), 230-265.

Uexküll, J. (1909). Umwelt und Innenwelt der Tiere. Berlin: Springer.

\section{SOBRE EL AUTOR}

Leo Peixoto Rodrigues. PhD em Sociologia, UFRGS. Professor Permanente dos Programas de Pós-Graduação em Sociologia e do Programa de Pós-Graduação em Ciência Política, Universidade Federal de Pelotas - UFPel.

CONTACTO

leo.peixotto@gmail.com 
112 | Leo Peixoto

Recibido: mayo 2017

Aceptado: agosto 2017

REVISTA MAD | MAGÍSTER EN ANÁLISIS SISTÉMICO APLICADO A LA SOCIEDAD

ISSN 0718-0527

Departamento de Antropología

Facultad de Ciencias Sociales

Universidad de Chile

ఏ. Avenida Capitán Ignacio Carrera Pinto 1045 Nuñ̃oa 7800284 | Santiago | Chile

(c) +56229787760

(a) revistamad.uchile@facso.cl

(\$) www.revistamad.uchile.cl

$\rightarrow$ RevMadUChile Twitter | Facebook 